\title{
Mindfulness and the Quality of Romantic Relationships: Is It All about Well-Being?
}

\author{
Peter M. Forster \\ Institute of Health \& Society, University of Worcester, Worcester, United Kingdom \\ Email: p.forster@worc.ac.uk
}

How to cite this paper: Forster, P.M. (2017) Mindfulness and the Quality of Romantic Relationships: Is It All about Well-Being? Open Journal of Social Sciences, 5, 59-63. https://doi.org/10.4236/jss.2017.55005

Received: March 23, 2017

Accepted: May 7, 2017

Published: May 10, 2017

Copyright $\odot 2017$ by author and Scientific Research Publishing Inc. This work is licensed under the Creative Commons Attribution-NonCommercial International License (CC BY-NC 4.0). http://creativecommons.org/licenses/by-nc/4.0/

\begin{abstract}
Studies have shown that mindfulness is positively associated with a number of individual factors related to well-being, attention and awareness, and life satisfaction. Mindfulness has also been shown to be positively associated with the perceived quality of romantic relationships. However, the factors underlying the connection between mindfulness and relationship quality are not well understood. A study is reported in which the connection between mindfulness and perceived relationship quality was investigated when individual life satisfaction was controlled for. The results suggest that individual life satisfaction partially mediates the association between mindfulness and relationship quality but that other factors also contribute to that association. Possible additional mediating factors and ideas for possible future studies that could throw light on this connection are discussed.
\end{abstract}

\section{Keywords}

Mindfulness, Relationship Quality, Life Satisfaction, Romantic Relationships

\section{Introduction}

Mindfulness has been defined as an open or a receptive attention to and awareness of what is taking place, both internally and externally, in the present [1]. Mindfulness has been shown to have psychological benefits. The latter study demonstrated a connection between mindfulness as a distinct construct and several dimensions of well-being, including lower neuroticism, anxiety, depression and negative affectivity, and higher positive affectivity, vitality, life satisfaction, self-esteem, optimism and self-actualisation.

Several authors have suggested that mindfulness may help in enhancing the quality of romantic relationships [2] [3] [4]. More specifically, Kabat-Zinn [5] 
and Welwood [6] suggested that mindfulness promotes attunement, connection, and closeness in relationships.

Barnes, Brown, Krusemark, Campbell and Rogge [7] found a positive connection between mindfulness and relationship satisfaction in romantic relationships. The mechanism of this effect is not clear, however. The authors suggested that future research could further investigate connections between mindfulness, relationship satisfaction and other outcome variables.

At an individual level, mindfulness has been shown to be positively associated with psychological well-being [1]. Looking more specifically at people in intimate relationships, there is evidence that mindfulness practices enhance individual well-being by increasing optimism, spirituality, relaxation and coping efficacy, and by reducing psychological distress and overall stress levels [8]. Barnes, Brown, Krusemark, Campbell and Rogge [7] found that mindfulness was associated with lower levels of post-discussion anxiety and stress in relationship partners.

So the link between mindfulness and relationship quality might be mediated by increased levels of individual well-being. However, mindfulness has also been shown to be related to more interpersonal skills such as social and communication skills that have the potential to enhance relationship quality [9]. Wachs and Cordova [10], for example, found that mindfulness was positively correlated with the ability to control the expression of one's emotions and also with levels of empathy, and Remmers, Topolinski and Koole [11] showed that mindfulness may enhance both implicit and explicit emotion regulation.

The aim of the present study is to clarify whether the link between mindfulness and relationship quality is mainly or completely accounted for by enhanced individual well-being. If the relationship between mindfulness and relationship quality is reduced or disappears when individual life satisfaction is controlled for then that indicates that the connection is mainly or entirely due to individual well-being.

\section{Method}

\subsection{Participants}

Participants were located by placing a request into an on-line noticeboard read by undergraduate and postgraduate psychology students at the author's university; by sending the request to Facebook contacts, Twitter followers and to participants in the online organisation, Click Worker. The request included the following information for potential participants:

If you are aged 18 years or over and are currently in a romantic relationship of 3 months or longer, we invite you to participate in this study designed to understand some of the factors which contribute to a successful relationship. If you decide to participate in the study, you can do so by completing a questionnaire consisting of 51 questions. Answering the questionnaire will take about 5 to 10 minutes of your time, although you can take as long 
as you like to answer the questions.

If you choose to take part you will complete an online survey that asks you

a series of questions about:

- Yourself, including how satisfied you are with life

- How you feel and think about your relationship.

Assurances of confidentiality were included, followed by a link to the on-line survey. Seventy-three participants responded and attempted the questionnaire, of whom 63 provided valid responses.

\subsection{Measures}

The Revised Dyadic Adjustment Scale (RDAS) [12] is a widely used 32-item measure of relationship quality based on Likert-type ratings of criteria such as agreement on activities and issues such as sex relations, philosophy of life, and religious matters. Previous studies have identified four subscale factors measuring marital satisfaction, degree of consensus between partners, amount of affectionate expression in the relationship, and dyadic cohesion, or the degree to which partners function as a team. However, the sub-scales were not used in the present study. The DAS has acceptable psychometric properties as an assessment device, with high (0.96) internal consistency [12].

The Satisfaction with Life Scale (SWL) [13] is a Likert-type, 5-item questionnaire designed to measure satisfaction with life as a whole. The present study required a global measure of life satisfaction rather than a specific measure such as happiness or positive affect. Life satisfaction has been defined as "a global assessment of a person's quality of life according to his chosen criteria" [14] (p. 478). The scale has acceptable psychometric properties. Diener, Emmons, Larsen, and Griffin [13] reported an alpha of 0.87 .

The Freiburg Mindfulness Inventory (FMI) [15] is a Likert-type, 14-item questionnaire designed to measure four components of mindfulness: cognitive, process, acceptance and non-judgmental stance. The internal consistency of the scale is high (0.86).

\subsection{Procedure}

The research ethics committee of the Institute of Health and Society at the University of Worcester provided ethical approval for the study. Those respondents who chose to participate completed the on-line questionnaire confirming the background variables (aged 18 years or over, and in a relationship with a duration of three months or longer), and the three scales described above.

\subsection{Statistical Analysis}

Data were analysed using IBM SPSS analysis software. A partial correlation was used to investigate the relationship between mindfulness, as measured by the Freiburg Mindfulness Inventory, and relationship satisfaction, as measured by the Revised Dyadic Adjustment Scale, while controlling for life satisfaction, as 
measured by the Satisfaction with Life Scale.

\section{Results}

A partial correlation was used to investigate the relationship between mindfulness and relationship satisfaction while controlling for life satisfaction (Table 1). Preliminary analyses were performed to explore normality, linearity and homoscedasticity and the negative kurtosis typically found in measures of life satisfaction and relationship satisfaction were observed.

A small to moderate, positive partial correlation was observed between mindfulness and relationship satisfaction after controlling for life satisfaction, $r=$ $0.258, \mathrm{n}=61, \mathrm{p}=0.022$.

The zero-order correlation, $\mathrm{r}=0.355, \mathrm{n}=62, \mathrm{p}=0.002$, indicated that controlling for life satisfaction had a clear effect on the strength of the relationship between mindfulness and relationship quality suggesting that some of the relationship between mindfulness and relationship quality could be accounted for by individual life satisfaction, but that other factors were also contributing to the relationship.

\section{Discussion}

The present study found the positive correlation between mindfulness and perceived relationship quality that has been observed elsewhere. Although this connection was still observed after controlling for individual life satisfaction, it was reduced, indicating that individual life satisfaction makes a major contribution to the link between mindfulness and relationship quality. However, the analysis also showed that life satisfaction is not the only factor that mediates the connection between mindfulness and relationship quality.

Plausible, potential candidates for other contributing factors described above include: improved social and communication skills; emotional regulation and control of emotional expression; and increased empathy. For future research, it would be worth looking more closely at the contribution these factors make to relationship quality and related factors such as the longevity of relationships.

A limitation of this study was the relatively high number of participants (10 out of 73) who provided invalid responses such as failing to answer all questions.

A potentially useful area of research would be to study the effects of couples engaging in mindfulness practices together. It would be worth knowing more about the effects of such interventions on broader factors such as relationship

Table 1. Mean scores and standard deviations of all variables.

\begin{tabular}{cc}
\hline Variable & Mean $(S D)$ \\
\hline Mindfulness (FMI) & $2.68(0.43)$ \\
Relationship satisfaction (RDAS) & $3.29(0.22)$ \\
Life satisfaction (SWL) & $4.93(1.40)$ \\
\hline
\end{tabular}


quality as well as on more specific dependent variables such as communication skills and levels of conflict.

\section{References}

[1] Brown, K.W. and Ryan, R.M. (2003) The Benefits of Being Present: Mindfulness and Its Role in Psychological Well-Being. Journal of Personality and Social Psychology, 84, 822-848. https://doi.org/10.1037/0022-3514.84.4.822

[2] Burpee, L.C. and Langer, E.J. (2005) Mindfulness and Marital Satisfaction. Journal of Adult Development, 12, 43-51. https://doi.org/10.1007/s10804-005-1281-6

[3] Flaxman, G. and Flook, L. (2008) Brief Summary of Mindfulness Research. Medicine, Health Care, and Society 6th Annual Conference, Worcester, 10-12 April 2008. http://marc.ucla.edu/workfiles/pdfs/MARC-mindfulness-research-summary.pdf

[4] Kozlowski, A. (2012) Mindful Mating: Exploring the Connection between Mindfulness and Relationship Satisfaction. Sexual and Relationship Therapy, 28, 1-13.

[5] Kabat-Zinn, J. (1993) Mindfulness Meditation: Health Benefits of an Ancient Buddhist Practice. In: Goleman, D. and Garin, J., Eds., Mind/Body Medicine, Consumer Reports, Yonkers, New York, 257-276.

[6] Welwood, J. (1996) Love and Awakening. HarperCollins, New York.

[7] Barnes, S., Brown, K.W., Krusemark, E., Campbell, W.K. and Rogge, R.D. (2007) The Role of Mindfulness in Romantic Relationship Satisfaction and Responses to Relationship Stress. Journal of Marital \& Family Therapy, 33, 482-500. https://doi.org/10.1111/j.1752-0606.2007.00033.x

[8] Carson, J.W., Carson, K.M., Gil, K.M. and Baucom, D.H. (2004) Mindfulness-Based Relationship Enhancement. Behavior Therapy, 35, 471-494. https://doi.org/10.1016/S0005-7894(04)80028-5

[9] Jones, S.M. and Hansen, W. (2014) The Impact of Mindfulness on Supportive Communication Skills: Three Exploratory Studies. Mindfulness, 6, 1115-1128. https://doi.org/10.1007/s12671-014-0362-7

[10] Wachs, K. and Cordova, J.V. (2007) Mindful Relating: Exploring Mindfulness and Emotion Repertoires in Intimate Relationships. Journal of Marital and Family Therapy, 33, 464-481. https://doi.org/10.1111/j.1752-0606.2007.00032.x

[11] Remmers, C., Topolinski, S. and Koole, S.L. (2016) Why Being Mindful May Have More Benefits Than You Realize: Mindfulness Improves Both Explicit and Implicit Mood Regulation. Mindfulness, 7, 829-837. https://doi.org/10.1007/s12671-016-0520-1

[12] Spanier, G.B. (1976) Measuring Dyadic Adjustment: New Scales for Assessing the Quality of Marriage and Similar Dyads. Journal of Marriage and Family, 38, 15-28. https://doi.org/10.2307/350547

[13] Diener, E., Emmons, R.A., Larsen, R.J. and Griffin, S. (1985) The Satisfaction With Life Scale. Journal of Personality Assessment, 49, 71-75. https://doi.org/10.1207/s15327752jpa4901_13

[14] Shin, D.C. and Johnson, D.M. (1978) Avowed Happiness as an Overall Assessment of the Quality of Life. Social Indicators Research, 5, 475-492. https://doi.org/10.1007/BF00352944

[15] Walach, H., Buchheld, N., Buttenmuller, V., Kleinknecht, N. and Schmidt, S. (2006) Measuring Mindfulness: The Freiburg Mindfulness Inventory (FMI). Personality and Individual Differences, 40, 1543-1555.

https://doi.org/10.1016/j.paid.2005.11.025 
Submit or recommend next manuscript to SCIRP and we will provide best service for you:

Accepting pre-submission inquiries through Email, Facebook, LinkedIn, Twitter, etc. A wide selection of journals (inclusive of 9 subjects, more than 200 journals)

Providing 24-hour high-quality service

User-friendly online submission system

Fair and swift peer-review system

Efficient typesetting and proofreading procedure

Display of the result of downloads and visits, as well as the number of cited articles Maximum dissemination of your research work

Submit your manuscript at: http://papersubmission.scirp.org/

Or contact jss@scirp.org 